\title{
MINDFULNESS SEBAGAI STRATEGI REGULASI EMOSI
}

\section{Cleoputri Yusainy, Ratri Nurwanti, Ignatius Ryan Jeffri Dharmawan, Riska Andari, Maria Ulfatul Mahmudah, Rizki Restuning Tiyas, Baiq Hanny Muthia Husnaini, dan Calvin Octavianus Anggono}

\author{
Jurusan Psikologi, Fakultas Ilmu Sosial dan Ilmu Politik, Universitas Brawijaya \\ Jl. Veteran, Malang, Indonesia 65145 \\ cleo.yusainy@ub.ac.id
}

\begin{abstract}
Research on emotional regulation has been dominated by a hedonist perspective, which argued that the existence of positive affects and the absence of negative affects is an indicator of optimal human functioning. Meeting hedonic needs, however, is not the only goal of emotional regulation. Emotional regulation can also facilitate the integrity of the personality-oriented function as a whole. Mindfulness as an emotional regulation strategy is escorted by attention to all that is taking place in the present moment with an attitude of acceptance, thereby facilitating person-oriented function by bringing emotional experiences towards neutrality. The effectiveness of brief induction of mindfulness in comparison with other strategies in Gross and Thompson's (2007) Process Model of Emotion Regulation (i.e., reappraisal, distraction, suppression) and control condition was tested in this randomized-mixed design experiment $(N=260)$ through self-reported ratings of affective valence for 60 positive, neutral, and negative photographs. The effectiveness of mindfulness was equivalent to positive reappraisal for positive stimulus, but lower than positive reappraisal for negative stimulus. Suppression consistently demonstrated equality of effectiveness with mindfulness, while distraction was as equally ineffective as control condition. These complex dynamics of emotional responding between mindfulness and other emotional regulation strategies requires further exploration.
\end{abstract}

Keywords: acceptance; affective valence; mindful emotion regulation; mindfulness; person-oriented functions

\begin{abstract}
Abstrak
Kebanyakan penelitian mengenai regulasi emosi diwarnai oleh perspektif hedonis, yang berpandangan bahwa keberadaan afek positif dan ketiadaan afek negatif merupakan indikator bagi fungsi optimal manusia. Pemenuhan kebutuhan hedonis hanyalah merupakan salah satu tujuan regulasi emosi. Regulasi emosi dapat pula berfungsi memfasilitasi integritas sistem kepribadian secara keseluruhan (person-oriented functions). Mindfulness sebagai suatu strategi regulasi emosi dikawal oleh atensi yang diberikan individu terhadap pengalamannya disertai penerimaan (acceptance) terhadap pengalaman tersebut sebagai episode hidup yang tidak perlu disikapi secara berlebihan, sehingga dapat memfasilitasi person-oriented function dengan cara mendekatkan afek menuju netral. Eksperimen dengan randomized mixed-design ini bertujuan untuk menguji sejauh mana efektivitas induksi ringkas mindfulness dibandingkan strategi lain dalam Process Model of Emotion Regulation (Gross \& Thompson, 2007 ) berupa positive reappraisal, distraction, dan suppression, serta kondisi kontrol. Partisipan $(N=260)$ memberikan rating valensi afek terhadap 60 foto dengan muatan emosional positif, netral, dan negatif. Efektivitas mindfulness setara dengan positive reappraisal untuk kategori stimulus positif, namun lebih rendah dibandingkan positive reappraisal untuk kategori stimulus negatif. Suppression secara konsisten menunjukkan kesetaraan efektivitas dengan mindfulness, sementara distraction sama tidak efektifnya dengan kondisi kontrol. Kompleksitas dinamika respons emosional antara mindfulness dan strategi regulasi emosi lain membutuhkan eksplorasi lebih jauh.
\end{abstract}

Kata kunci: acceptance; mindful emotion regulation; mindfulness; person-oriented functions; valensi afek

\section{PENDAHULUAN}

Eksistensi manusia hingga detik ini tidak dapat lepas dari pengaruh emosi. Dorongan alamiah seperti mengasuh (CARE) dan seksualitas/berkembang biak (LUST) adalah 
contoh emosi dasar manusia (Panksepp \& Biven, 2012). Emosi dengan keragaman jenisnya, dan afek (perasaan emosional yang intens), telah muncul di dalam kesadaran kita sejak lahir serta dibutuhkan untuk fungsi pertahanan hidup. Seiring berjalannya waktu, pemaknaan manusia terhadap pengalaman emosionalnya melebar lebih dari sekadar untuk bertahan hidup. "Warna" menyenangkan (afek positif) maupun tidak menyenangkan (afek negatif) yang diberikan manusia terhadap pengalaman emosionalnya mendorong terciptanya berbagai produk kreatif dan imajinatif yang semakin memajukan peradaban.

Untuk menjelaskan mengenai mekanisme yang mendasari pembentukan dan pemrosesan emosi-afek, perlu dipahami bahwa pengalaman emosional melibatkan aktivasi jaringan saraf di area neokortikal dan subkortikal, sebagai dasar bagi perubahan aspek-aspek motor-ekspresif, sensorisperseptual, otonomi-hormonal, kognitifatensi, dan perasaan afektif (Bradley \& Lang, 2007). Neokortikal (termasuk prefrontal cortex) adalah otak bagian atas yang berfungsi sebagai generator kemampuan kognitif yang secara evolusioner baru berkembang belakangan, setelah perkembangan daerah subkortikal seperti amigdala, hipokampus, dan periaqueductal gray (Panksepp \& Biven, 2012). Lebih spesifik, aktivitas amigdala sendiri merepresentasikan pembentukan pengalaman emosional dan mencerminkan berbagai pemrosesan informasi emosional yang berkaitan dengan pengalaman emosional (Anderson, 2007), hipokampus berfungsi untuk mendorong dan mempertahankan respons emosional yang tepat (ImmordinoYang \& Singh, 2013), dan peraqueductal gray matter berfungsi dalam pemroresan rasa takut, cemas, dan rasa sakit (Venkatraman, Edlow, \& Immordino-Yang 2017; Buhle dkk., 2013).

Afek yang muncul sebagai konsekuensi pemaknaan kognisi terhadap pengalaman emosional menjadi tidak adaptif ketika berlebihan dalam hal intensitas, bertahan dalam waktu lama, muncul secara tidak terduga, atau tidak sesuai dengan konteks situasi (Phan \& Sripada, 2013). Sebagai contoh, afek negatif berupa kemarahan secara signifikan meningkatkan resiko berkendara dengan bertambahnya kecepatan saat mengemudi (Hu, Xie, \& Li, 2013). Dengan demikian, diperlukan strategi yang memungkinkan individu meregulasi emosi secara lebih adaptif. Regulasi emosi dapat dipahami sebagai proses intervensi secara sadar maupun tidak sadar terhadap pengalaman emosional yang memungkinkan perubahan pengalaman dan ekspresi afek dari respons natural menjadi respons lain yang lebih efektif (Gross \& Thompson, 2007; Phan \& Sripada, 2013). Kegagalan regulasi emosi muncul pada beragam ganguan psikiatri seperti depresi mayor, bipolar, kecemasan, dan borderline (Aldao, Nolen-Hoeksema, \& Schweizer, 2010).

Process Model of Emotion Regulation dari Gross dan Thompson (2007; Gambar 1) menggambarkan bahwa regulasi emosi mungkin terjadi sebelum kemunculan respons (antecendent-focused strategies) maupun sesudah kemunculan respons afektif/perilaku (response-focused strategies). Meta-analisis terhadap model ini menyimpulkan bahwa secara umum, strategi berbasis anteseden merupakan strategi yang lebih efektif dibandingkan strategi berbasis respons (Webb, Miles, \& Sheeran, 2012).

Reappraisal, varian dari strategi berbasis anteseden yang melibatkan perubahan interpretasi terhadap stimulus untuk mengubah pengaruh afektifnya, merupakan strategi regulasi emosi yang sangat populer. Strategi ini efektif karena memanfaatkan kontrol kognitif untuk memodulasi representasi makna dari stimulus afektif, sehingga pada gilirannya menurunkan aktivitas pada amigdala (Buhle dkk., 2014). Reappraisal secara umum ditujukan untuk mereduksi afek negatif (negative reappraisal) atau untuk meningkatkan afek positif (positive reappraisal). Dalam literatur klasik 
mengenai stres, positive reappraisal adalah menghadapi situasi yang menimbulkan stres langkah pertama yang dibutuhkan untuk (Folkman, 1997).

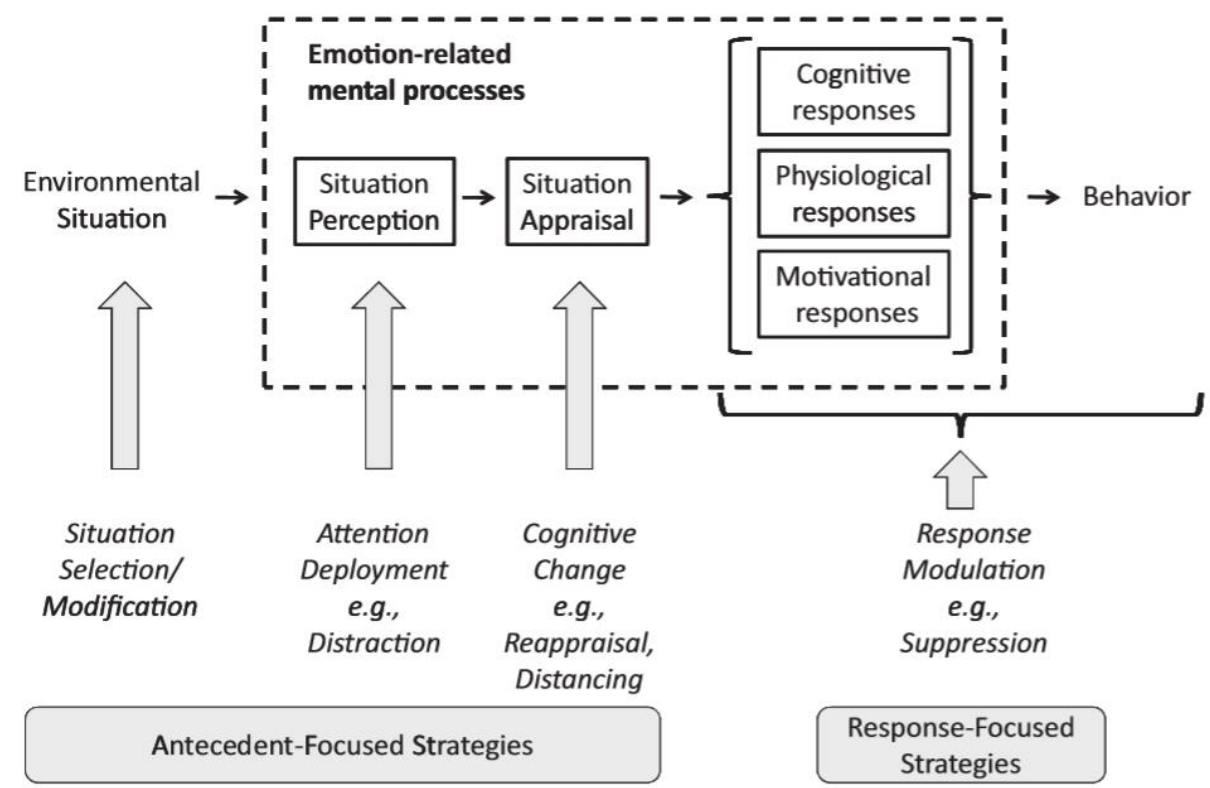

Gambar 1. Skema strategi regulasi emosi (Phan \& Sripada, 2013, hlm. 378. Modifikasi dari Process Model of Emotion Regulation: Gross \& Thompson, 2007).

Strategi berbasis anteseden lain berupa distraction, yaitu mengalihkan atensi terhadap aspek yang berbeda dari suatu stimulus untuk menurunkan dampak emosionalnya. Pengalihan perhatian bisa dilakukan secara fisik (misalnya, menutup mata) maupun mental (memikirkan hal lain yang tidak ada kaitannya dengan stimulus). Di balik kemudahan dan kesederhanaan metodenya, distraction juga mampu mereduksi afek negatif yang dilaporkan individu dan aktivitas amigdala dalam pemrosesan stimulus afektif (McRae dkk., 2010). Dibandingkan reappraisal, efek yang ditimbulkan oleh distraction lebih bersifat jangka pendek (Buhle dkk., 2014). Selain itu, distraction dapat menjadi tidak adaptif ketika terus-menerus digunakan untuk menghindari pengalaman emosional (Wolgast \& Lundh, 2017).

Varian dari strategi berbasis respons yang populer adalah suppression, yaitu modulasi respons kognitif, fisiologis, atau perilaku terhadap suatu stimulus afektif (Gross \& Thompson, 2007). Berbeda dengan reappraisal dan distraction, suppression dilakukan setelah respons afektif terbentuk, sehingga regulasi ini justru dapat meningkatkan aktivitas pada area amigdala dan insula (Kim \& Hamann, 2007). Suppression diketahui memiliki asosiasi positif dengan berbagai simtom psikopatologis (Aldao dkk., 2010).

Perlu digarisbawahi bahwa strategi regulasi emosi tidak hanya penting diterapkan pada afek negatif, namun juga pada afek positif. Beragam konstruk seperti kesejahteraan ("well-being"), kebahagiaan ("happiness"), dan kehidupan yang baik ("good life") memiliki asosiasi dengan afek positif (Tamir \& Gross, 2011). Bahkan, secara umum penelitian mengenai efektivitas strategi regulasi emosi didominasi oleh perspektif hedonis, yang berpandangan bahwa fungsi optimal manusia ditandai oleh keberadaan afek positif dan ketiadaan afek negatif (Diamond \& Aspinwall, 2003). Meskipun afek positif dibutuhkan untuk kualitas hidup yang baik, jenis afek ini dapat membawa konsekuensi yang merugikan seperti meningkatkan kecenderungan perilaku berisiko (penyalahgunaan alkohol dan obatobatan, seks bebas), mengurangi empati, dan menurunkan kemampuan penalaran (Gruber, 
2011). Eksperimen Yusainy (2017) terhadap mahasiswa di Indonesia juga menemukan bahwa hipersensitivitas terhadap stimulus afektif yang dianggap menyenangkan memiliki asosiasi dengan peningkatan kecenderungan untuk berfokus pada dunia luar dan terus-menerus memberikan kritik terhadap diri sendiri.

Koole (2009) menyimpulkan bahwa pemenuhan kebutuhan hedonis hanyalah merupakan salah satu dari fungsi regulasi emosi. Dalam perspektif eudaimonic, regulasi emosi dapat diarahkan untuk mendorong manusia mencapai tujuan dan aspirasi personalnya (Ryan \& Deci, 2000). Upaya pencapaian tujuan (goal-oriented functions) seringkali menuntut kemampuan untuk mentoleransi keberadaan afek negatif. Menurut teori klasik feedback loops (Carver \& Scheier, 1982), afek negatif dibutuhkan untuk mengaktivasi self-control agar proses mental dan perilaku agar sejalan dengan norma sosial dan standar personal. Lebih jauh, regulasi emosi dapat pula berfungsi memfasilitasi integritas sistem kepribadian (person-oriented functions). Regulasi personoriented functions ditandai dengan integrasi keseluruhan pengalaman emosional secara utuh, berbeda dengan regulasi untuk memenuhi kebutuhan hedonis dan goaloriented function yang terfokus pada aspek emosional atau tugas yang bersifat spesifik (Koole, 2009).

Mindfulness ("sadar penuh-hadir utuh": Silarus, 2015) adalah atensi yang diberikan individu terhadap pengalamannya disertai penerimaan (acceptance) terhadap pengalaman tersebut (Hayes, Follette, \& Linehan, 2004). Konsep mindfulness berakar dari tradisi kontemplasi dan praktik meditasi Timur. Melalui mindfulness, setiap pengalaman yang muncul saat ini ("here-andnow") diberi atensi penuh tanpa upaya untuk mengubah pemikiran, sensasi tubuh, maupun afek yang muncul akibat pengalaman tersebut. Walaupun terkesan kontraintuisi, upaya untuk tidak mengubah respons akibat pengalaman emosional ini pada gilirannya dapat mengurangi kebiasaan untuk merespons dengan cara-cara reaktif (Baer, 2003; Shapiro, Carlson, Astin \& Freedman, 2006; Yusainy dkk., 2018). Karena itu mindfulness, terutama komponen acceptance dalam mindfulness, digolongkan sebagai strategi regulasi emosi (Dan-Glauser \& Gross, 2015).

Studi meta-analisis dan tinjauan sistematis telah menyimpulkan manfaat mindfulness pada level trait maupun pada efek jangka panjang pelatihan dan intervensi berbasis mindfulness (Gotink, Chu, Busschbach, Benson, Fricchione, \& Hunink, 2015; Gu, Strauss, Bond, \& Cavanagh, 2015; Keng, Smoski, \& Robins, 2011). Sebagian dari manfaat ini diduga dapat muncul juga pada konteks induksi mindfulness ringkas (brief mindfulness induction). Segera setelah induksi regulasi emosi mindfulness, partisipan menunjukkan penurunan reaktivitas dalam afek positif (Lalot, Delplanque, \& Sander, 2014) maupun negatif (Arch \& Craske, 2006). Mindfulness dapat mendekatkan afek menuju netral karena individu tidak terlalu erat mempertahankan maupun menghindari pengalamannya (Hayes \& Feldman, 2004); pengalaman emosional dihadapi secara terbuka sebagai suatu hal yang tidak perlu disikapi secara berlebihan.

Mindfulness dapat muncul pada berbagai fase regulasi emosi, sehingga sulit dipetakan secara spesifik ke dalam Process Model of Emotion Regulation (Phan \& Sripada, 2013). Tinjauan Guendelman, Medeiros, dan Rampes (2017) menyimpulkan bahwa mekanisme neural pada regulasi mindfulness melibatkan kombinasi proses "top-down" area neokortikal yang berbasis kognisi, atensi, kontrol kognitif, dan monitor pengalaman secara sadar, serta proses "bottom-up" area subkortikal berupa modulasi properti sensoris-perseptual dari stimulus afektif. Koordinasi antara proses top-down dan bottom-up ini sejalan dengan fungsi regulasi emosi mindfulness untuk memfasilitasi person-oriented function (Koole, 2009). Asosiasi negatif telah ditemukan antara 
komponen acceptance dengan simtom psikopatologis (Aldao dkk., 2010).

Efektivitas mindfulness dalam penelitian ini dibandingkan dengan positive reappraisal, suppression, dan distraction. Sebagai baseline, penelitian ini juga melibatkan kondisi kontrol yang tidak melakukan regulasi emosi. Efektivitas suatu strategi regulasi emosi mungkin berbeda tergantung pada kategori valensi stimulus afektif. Regulasi afek bervalensi positif secara umum lebih mudah dibandingkan regulasi afek negatif, sedangkan upaya memperkuat (upregulation) atau memperlemah (downregulation) valensi afek yang sudah dirasakan lebih mudah daripada mengubah valensi afek menjadi kebalikan dari valensi yang dirasakan (Kim \& Hamann, 2007). Efektivitas mindfulness diujikan untuk meregulasi stimulus afektif dengan valensi positif dan negatif relatif terhadap stimulus netral. Mindfulness dapat disimpulkan sebagai sebagai suatu strategi regulasi emosi yang efektif ketika mendekatkan rating afektif yang dilaporkan partisipan terhadap stimulus positif maupun negatif ke arah netral.

\section{METODE}

\section{Desain dan Partisipan}

Penelitian ini menggunakan randomised mixed-design, dengan kategori valensi foto sebagai variabel within-subjects (2: foto bervalensi positif vs. negatif) dan strategi regulasi emosi sebagai variabel betweensubjects (5: mindful emotion regulation (MER) vs. positive reappraisal emotion regulation (PRER) vs. suppression emotion regulation (SER) vs. distraction emotion regulation (DER) vs. no emotion regulation (NER/kondisi kontrol). Dari 282 mahasiswa peserta matakuliah A pada Universitas B yang dijadwalkan mengikuti eksperimen, 22 partisipan mengalami eliminasi akibat ketidakhadiran, ketidakpatuhan, dan kesalahan teknis sehingga total partisipan final berjumlah 260 orang ( $M$ usia $=18,31$, $S D=0,865)$. Alokasi partisipan final adalah 51 mahasiswa $(32,075 \%$ laki-laki) pada kondisi MER, 55 mahasiswa $(27,273 \%$ lakilaki) pada kondisi PRER, 53 mahasiswa (33,963\% laki-laki) pada kondisi SER, 53 mahasiswa $(39,623 \%$ laki-laki) pada kondisi DER, dan 48 mahasiswa $(29,167 \%$ laki-laki) pada kondisi NER.

\section{Prosedur}

Partisipan hadir di laboratorium komputer secara berkelompok berdasarkan alokasi kondisi strategi regulasi emosi yang telah ditetapkan secara acak. Setelah membaca informasi mengenai eksperimen, partisipan menandatangani formulir persetujuan, mengisi data demografis, serta mengisi kuesioner strategi regulasi emosi yang biasa mereka gunakan sehari-hari (3 butir pertanyaan, contoh: "Strategi apa yang biasanya Anda terapkan ketika Anda sedang merasa marah akibat perlakuan yang tidak adil?"; setiap butir disertai pilihan jawaban yang menggambarkan strategi regulasi emosi yang dibandingkan dalam penelitian ini). Kuesioner ini diberikan sekadar untuk mempermudah pemberian instruksi selanjutnya. Partisipan kemudian menerima stimulus visual berupa foto-foto dari International Affective Picture System (IAPS: Lang, Bradley, \& Cuthbert, 2008). Setiap foto ditayangkan pada layar komputer secara acak selama lima detik, kemudian mereka diberikan waktu selama tujuh detik untuk memberikan penilaian terhadap valensi masing-masing foto. Penyajian stimulus IAPS (Tabel 1) diawali dengan 3 foto pada sesi attend untuk perhitungan baseline level valensi afek positif, netral, dan negatif. Pada sesi practice (6 foto) dan regulate (60 foto), partisipan diminta menerapkan strategi regulasi emosi yang sesuai untuk kondisi perlakuan yang mereka terima. Pada akhir eksperimen ditayangkan video humor berdurasi dua menit tentang instant gratification experiment (https://youtu.be/Yo4WF3cSd9Q) untuk penetral dampak dari stimulus yang disajikan. Debrief mengenai hipotesis penelitian dilakukan bersamaan dengan pemberian nilai kredit $10 \%$ dari total nilai akhir partisipan pada matakuliah A. 
Tabel 1.

Struktur dan Properti psikometri International Affective Picture System (IAPS; Lang dkk., 2008)

\begin{tabular}{llllll}
\hline \multirow{2}{*}{ Sesi } & Kategori & \multirow{2}{*}{ Nomor Foto } & \multicolumn{3}{c}{ Rating Afektif Partisipan } \\
& Foto & & $M$ & $(S D)$ & $\alpha$ \\
\hline Attend & Netral & 7059 & 20,969 & $(19,781)$ & \\
& Positif & 1710 & 4,675 & $(15,327)$ & \\
& Negatif & 9410 & $-6,525$ & $(33,167)$ & \\
& Netral & 7061 & & & \\
& Practice & - & & & \\
& Nesitif & - & & & \\
& Negatif & $9490,9570,9635.1,9941$ & & & \\
Regulate* & Netral & $2381,2480,2702,2830,2870,2880,2890,5395,7004$, & 6,180 & $(6,832)$ & 0,754 \\
& & $7020,7160,7182,7237,7491,7546,7590,7595,7950$, & & & \\
& 9422,9700 & & & \\
& Positif & $1603,1604,1812,2165,2270,2341,2394,2580,4572$, & 23,898 & $(9,057)$ & 0,875 \\
& $4614,5594,5711,5831,5994,7238,7325,7509,8117$, & & & \\
& 8496,8502 & & & \\
& Negatif & $2221,2682,2722,2751,3061,3062,3261,4621,5120$, & $-16,922$ & $(11,111)$ & 0,895 \\
& $6241,6242,6244,6571,9041,9045,9101,9102,9253$, & & & \\
\hline
\end{tabular}

Keterangan: Angka empat digit menunjukkan nomor foto IAPS yang telah dilengkapi dengan $M$ dan $S D$ untuk dimensi valensi dari studi normatif IAPS. Sebagian besar foto berasal dari set foto nomer 9 IAPS, dengan penggantian beberapa foto yang mengandung konten tematik erotis dengan foto dari set lain karena mempertimbangkan latar belakang partisipan mahasiswa Indonesia. Urutan foto disajikan secara acak.

Rating afektif berkisar antara skor -50 (valensi paling negatif) sampai +50 (valensi paling positif).

\section{Instrumen}

Instruksi induksi strategi regulasi emosi diadaptasi dan dimodifikasi dari eksperimen sebelumnya (Hofmann, Heering, Sawyer, \& Asnaani, 2009; Lalot dkk., 2014; Thiruchselvam, Blechert, Sheppes, Rydstrom, \& Gross, 2011). Sejalan dengan komponen spesifik acceptance yang menjadi fokus dalam penelitian ini, partisipan pada kondisi MER diminta menganggap stimulus yang disajikan sebagai hal yang biasa ditemui dalam hidup, sehingga tidak perlu dibesarbesarkan dan cukup disikapi biasa saja. Kondisi PRER diminta mengambil sisi positif dari stimulus yang dilihat, terlepas dari seburuk apapun stimulus tersebut. Kondisi DER diminta untuk mengalihkan perhatian dengan cara menutup mata atau memikirkan tentang hal lain setelah partisipan melihat gambar yang membuat ia merasa tidak nyaman. Kondisi SER diminta untuk tidak menunjukkan ekspresi wajah apapun sehingga orang lain tidak mengetahui apa yang sebetulnya partisipan rasakan saat melihat stimulus. Kondisi NER/kondisi kontrol hanya diberikan instruksi untuk mengamati stimulus yang disajikan.

Stimulus afektif dapat disajikan dalam bentuk foto, suara, film, stimulus verbal atau tertulis, refleksi autobiografi terhadap pengalaman emosional sebelumnya, umpan balik negatif, dan tugas yang menimbulkan stres (Webb dkk., 2012). Dalam penelitian ini, pengalaman emosional partisipan dibangkitkan melalui paparan terhadap fotofoto IAPS dari Lang dkk. (2008). Dibandingkan stimulus afektif berbentuk film atau cerita yang mengandung gerakan, narasi, dan perubahan dinamis lain, foto yang bersifat statis memiliki parameter fisik yang lebih terkontrol dalam hal ukuran, durasi, warna, dan pencahayaan (Bradley \& Lang, 2007).

Sejalan tujuan penelitian, mean rating valensi normatif yang tersedia pada manual IAPS Peneliti klasifikasikan ke dalam tiga kelompok, yaitu skor $<4$ sebagai foto negatif, skor 4-6 sebagai foto netral, dan skor $>6$ 
sebagai foto positif (lihat Tabel 1). Dimensi valensi dari setiap foto IAPS dinilai oleh partisipan dengan menggunakan Affect Scale yang bergerak dari skor -50 untuk valensi paling negatif/tidak menyenangkan hingga +50 untuk valensi paling positif/menyenangkan (Arch \& Craske, 2006; Cho, Lee, Oh, \& Soto, 2017). Instrumen IAPS dan Affect Scale dipresentasikan di layar komputer dengan menggunakan aplikasi PsychoPy 1.80.03 (Peirce, 2009).

\section{HASIL DAN PEMBAHASAN}

Mixed ANOVA untuk menguji pengaruh kategori valensi foto sebagai variabel withinsubjects dan strategi regulasi emosi sebagai variabel between-subjects terhadap rating valensi afek dilakukan pada sesi attend dan sesi regulate (Tabel 2). Untuk mengetahui reaktivitas partisipan relatif terhadap stimulus afektif netral, rating afektif kategori foto bervalensi positif/negatif diperoleh dari selisih antara rating foto positif/negatif dan foto netral. Profile plots interaksi disajikan pada Gambar 2 (bagian kiri untuk sesi attend dan kanan untuk sesi regulate).

Pada sesi attend, rating partisipan berbeda berdasarkan kategori valensi foto $(F(1,250)$ $=123,929, p<0,001)$, dengan rating foto bervalensi positif lebih tinggi dibandingkan rating foto bervalensi negatif ( $t=11,197, p<$ $0,001)$. Hal ini menandakan bahwa relatif terhadap foto netral, perbedaan kategori valensi foto positif dan negatif berhasil membangkitkan respons afektif sesuai dengan arah yang diharapkan. Partisipan pada kelima kondisi strategi regulasi emosi memberikan rating afektif yang setara $(F(4$, $250)=0,715, p=0,582, n s$.). Artinya alokasi partisipan secara acak ke dalam kondisi MER (mindful emotion regulation), PRER (positive reappraisal emotion regulation), $\mathrm{SER}=$ suppression emotion regulation), DER (distraction emotion regulation), dan NER (no emotion regulation/kondisi kontrol) berhasil menciptakan kesetaraan baseline level valensi afek. Rating partisipan tidak dipengaruhi interaksi kategori valensi foto dan strategi regulasi emosi $(F(4,250=0,943$, $p=0,439, n s$.$) .$

Tabel 2.

Rating Afektif Partisipan terhadap Kategori Valensi Foto Berdasarkan Strategi Regulasi Emosi

\begin{tabular}{lllllll}
\hline Kategori foto & Kondisi & \multicolumn{2}{l}{ Rating afektif sesi attend } & \multicolumn{3}{l}{ Rating afektif sesi regulate } \\
& & $M$ & $(S D)$ & $M$ & $(S D)$ & $\alpha$ \\
\hline Bervalensi positif* & MER & 14,780 & $(23,591)$ & 16,104 & $(8,236)$ & 0,899 \\
& PRER & 23,463 & $(25,187)$ & 17,407 & $(6,975)$ & 0,886 \\
& SER & 12,981 & $(26,775)$ & 15,078 & $(7,536)$ & 0,866 \\
& DER & 15,885 & $(21,641)$ & 19,525 & $(6,654)$ & 0,819 \\
& NER & 13,787 & $(23,420)$ & 20,593 & $(6,808)$ & 0,768 \\
\hline Bervalensi negatif** & MER & $-7,800$ & $(36,687)$ & $-22,614$ & $(10,831)$ & 0,881 \\
& PRER & $-10,019$ & $(38,406)$ & $-18,345$ & $(9,691)$ & 0,916 \\
& SER & $-9,558$ & $(34,694)$ & $-19,321$ & $(11,177)$ & 0,835 \\
& DER & $-16,538$ & $(35,420)$ & $-27,917$ & $(8,754)$ & 0,829 \\
& NER & $-12,085$ & $(34,198)$ & $-27,963$ & $(7,535)$ & 0,696 \\
\hline
\end{tabular}

Keterangan: *Rating foto positif minus netral. ** Rating foto negatif minus netral.

$\mathrm{MER}=$ mindful emotion regulation; $\mathrm{PRER}=$ positive reappraisal emotion regulation; $\mathrm{SER}=$ suppression emotion regulation; $\mathrm{DER}=$ distraction emotion regulation; $\mathrm{NER}=$ no emotion regulation (kondisi kontrol).

Kondisi strategi regulasi MER ditempatkan sebagai reference group.

Pada sesi regulate, kategori valensi foto secara konsisten memengaruhi rating partisipan $(F(1,255)=2118,266, p<0,001)$, dengan rating foto bervalensi positif lebih tinggi dibandingkan rating foto bervalensi negatif ( $t=42,715, p<0,001)$. Rating partisipan dipengaruhi pula oleh strategi regulasi emosi $(F(4,255)=5,319, p<0,001)$. 
Lebih jauh, rating partisipan dipengaruhi interaksi antara kategori valensi foto dan strategi regulasi emosi $(F(4,255)=10,966, p$ $<0,001)$.

Analisis lanjutan terhadap sesi regulate menemukan bahwa pada foto bervalensi positif, rating MER lebih rendah dibandingkan DER $(t=2,402, p=0,017)$ dan NER $(t=3,073, p=0,002)$, namun setara dengan PRER $(t=0,973, p=0,357, n s$.$) dan$ $\operatorname{SER}(t=-0,720, p=0,472, n s$.$) dan NER (t=$ 1,666, $p=0,097)$. Pada foto bervalensi negatif, rating MER lebih rendah dibandingkan PRER $(t=-2,866, p=0,005)$, lebih tinggi dibandingkan DER $(t=-2,782, p$ $=0,006)$ dan NER $(t=-2,737, p<0,001)$, namun tidak berbeda dengan SER $(t=1,727$, $p=0,085, n s$.).
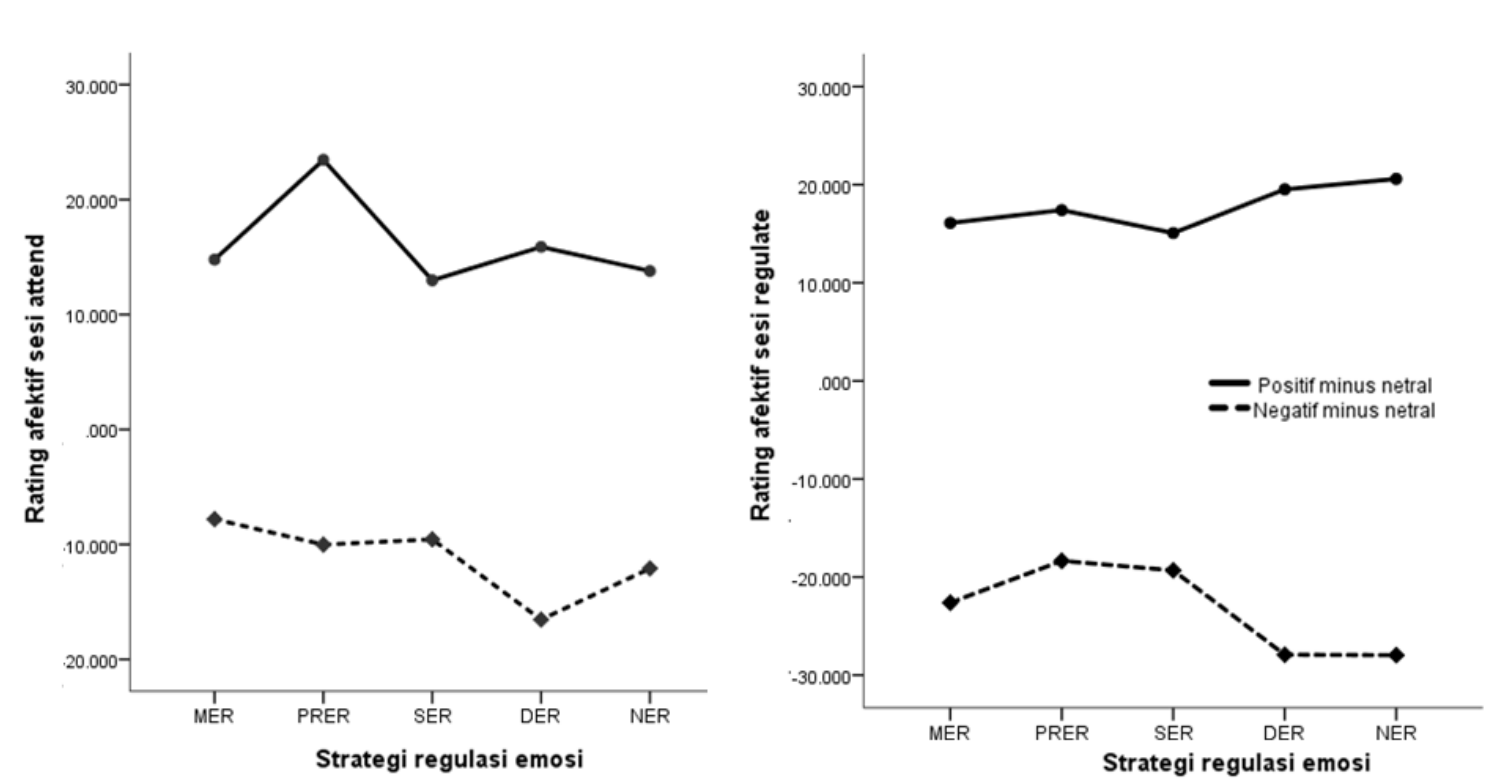

Gambar 2. Perbandingan Rating Afektif terhadap Kategori Foto Berdasarkan Strategi Regulasi Emosi pada Sesi Attend (Kiri) dan Regulate (Kanan), Relatif Terhadap Foto Netral

Keterangan: $\mathrm{MER}=$ mindful emotion regulation $; \mathrm{PRER}=$ positive reappraisal emotion regulation $; \mathrm{SER}=$ suppression emotion regulation; $\mathrm{DER}=$ distraction emotion regulation; $\mathrm{NER}=$ no emotion regulation (kondisi kontrol)

Efektivitas strategi regulasi emosi mindfulness dalam penelitian ini dibandingkan dengan tiga strategi lain yang populer yaitu positive reappraisal, distraction, dan suppression, serta kondisi kontrol yang tidak diminta melakukan regulasi apapun. Untuk stimulus bervalensi positif, rating afektif partisipan kondisi mindfulness setara dengan kondisi positive reappraisal dan suppression, namun lebih mendekati netral dibandingkan distraction dan kondisi kontrol. Kesetaraan efektivitas mindfulness dan positive reappraisal serupa dengan temuan Lalot dkk. (2014) bahwa mindfulness dan reappraisal sama-sama dapat menurunkan rating afektif positif dan ekspresi wajah yang berasosiasi dengan afek positif. Dalam penelitian Lalot dkk., instruksi reappraisal yang digunakan bersifat umum (bukan positive reappraisal) karena partisipan diminta mengambil jarak dari stimulus afektif namun tidak diarahkan untuk mencari makna yang lebih positif dari stimulus tersebut. Dalam penelitian ini, kondisi positive reappraisal diinstruksikan mengambil sisi positif dari stimulus positif yang disajikan, sehingga melakukan upregulation terhadap stimulus bervalensi positif. Studi di bidang neurosains menemukan bahwa up-regulation afek positif mengaktivasi area ventromedial prefrontal cortex (vMPFC) yang berasosiasi dengan 
pemrosesan informasi yang terkait diri sendiri (self-referential processing: Kim \& Hamann, 2007). Sebaliknya, partisipan yang mengikuti pelatihan mindfulness selama 8 minggu menunjukkan penurunan aktivitas pada vMPFC, sekaligus peningkatan kemampuan analisis yang lebih objektif terhadap pengalaman emosional internal (insula) dan eksternal (somatosensory cortex: Farb dkk., 2007). Implikasi dari perbedaan ini adalah meskipun pada penelitian ini efek jangka pendek dari regulasi emosi mindfulness terhadap kategori stimulus positif setara dengan positive reappraisal, mekanisme yang mendasari temuan ini belum tentu sama.

Untuk stimulus bervalensi negatif, efektivitas mindfulness lebih rendah dibandingkan positive reappraisal. Temuan ini sejalan dengan penelitian terdahulu konteks regulasi emosi marah (Szasz, Szentagotai, \& Hofmann, 2011) dan cemas (Hofmann dkk., 2009), yang menemukan bahwa reappraisal lebih unggul dibandingkan komponen acceptance yang menjadi kunci instruksi partisipan dalam penelitian ini. Sebagai sebuah proses yang bergerak dari regulasi yang bersifat top-down menjadi bottom-up (Guendelman dkk., 2017), efektivitas mindfulness tergantung pada seberapa familer seseorang terhadap praktik mindfulness (Chiesa, Serretti, \& Jakobsen, 2013). Ketika dihadapkan pada pengalaman emosional negatif, partisipan mahasiswa yang diasumsikan awam terhadap praktik formal mindfulness mungkin lebih terbiasa untuk melakukan positive reappraisal ("mengambil sisi positif dari stimulus yang dilihat"). Bias optimisme terhadap kemungkinan terjadinya hal-hal baik dalam kehidupan seberapapun buruknya kondisi saat ini ditemukan pada hampir $80 \%$ populasi (Sharot, 2011). Selain itu, beberapa eksperimen menemukan bahwa manfaat mindfulness tidak dapat segera terukur (immediate effect) dalam bentuk penurunan reaktivitas terhadap stimulus negatif, namun dalam bentuk potensi recovery yang lebih baik (delayed effect) pasca paparan stimulus negatif (Beblo dkk., 2018; Cho dkk., 2017).
Kesetaraan efektivitas mindfulness dan suppression dalam mendekatkan partisipan penelitian ini ke arah afek netral patut dicermati. Dilihat dari fungsinya, suppression merupakan regulasi yang bersifat goaloriented functions untuk memodulasi respons tubuh sementara mindfulness bersifat personoriented functions untuk mengintegrasikan pengalaman terhadap stimulus sensorisperseptual, kognisi, dan emosi secara utuh (Koole, 2009). Riset terdahulu menyimpulkan bahwa acceptance dan suppression memiliki efek yang belawanan dalam konteks pengalaman, ekspresi, dan respons fisiologis terhadap stimulus afektif (Dan-Glauser \& Gross, 2015) serta asosiasi dengan simtom patologis (Aldao dkk., 2010). Walaupun dalam riset tersebut acceptance lebih bermanfaat dibandingkan suppression, regulasi emosi yang diadopsi individu tidak terlepas dari latar belakang budaya individu yang bersangkutan. Pada masyarakat Asia yang menekankan interdependensi, suppression ternyata tidak memiliki asosiasi dengan fungsi psikologis yang buruk (Soto, Perez, Kim, Lee, \& Minnick, 2011) dan bahkan dianggap sebagai upaya adaptif untuk mencapai keharmonisan sosial (Butler, Lee, \& Gross, 2007; Ford \& Mauss, 2015). Eksperimen Keng, Tan, Eisenlohr-Moulb, dan Smoski (2017) terhadap mahasiswa di Singapura menemukan bahwa saat meregulasi pengalaman emosional yang membangkitkan kesedihan, partisipan dalam kondisi suppression yang memiliki nilai kultural Asia yang tinggi melaporkan rating kesedihan yang lebih rendah dibandingkan kondisi mindfulness. Sebaliknya, regulasi emosi mindfulness lebih memfasilitasi mood recovery dan tugas yang membutuhkan kemampuan kognitif daripada suppression, terlepas dari nilai kultural partisipan (Keng dkk., 2017)

Partisipan dalam kondisi distraction secara konsisten melaporkan reaktivitas yang lebih tinggi (skor afek menjauhi netral) dibandingkan kondisi mindfulness, baik terhadap kategori stimulus positif maupun 
negatif. Efektivitas distraction sebagai strategi regulasi emosi cenderung kontroversial, namun upaya manusia untuk mengubah pengalaman emosionalnya membawa pada risiko terjadinya pergulatan internal dengan pengalaman tersebut. Penelitian sebelumnya menemukan bahwa distraction meningkatkan reaktivitas ketika individu dihadapkan kembali dengan stimulus afektif yang sebelumnya ia hindari (Thiruchselvam dkk., 2011). Distraction yang dilakukan secara terus-menerus membutuhkan energi yang besar (Van Dillen \& Papies, 2015), sekaligus menutup kesempatan individu untuk membangun pemahaman terhadap pengalaman yang dibutuhkan untuk proses adaptasi (Wilson \& Gilbert, 2008). Sebagai implikasinya, penggunaan distraction perlu dibarengi dengan intensi untuk segera kembali menghadapi pengalaman yang sejenak dihindari (Wolgast \& Lundh, 2017). Seperti halnya distraction, kondisi kontrol dalam penelitian ini yang tidak diminta melakukan regulasi spesifik memberikan rating yang reaktif terhadap stimulus afektif.

Partisipan penelitian ini adalah mahasiswa S1 sehingga temuan yang dihasilkan tidak dapat digeneralisasi pada populasi komunitas maupun populasi klinis. Instruksi regulasi emosi mindfulness dalam penelitian ini terbatas pada komponen acceptance atas pengalaman emosional, sehingga ada kemungkinan partisipan tidak dapat menangkap spektrum lain dari praktik mindfulness seperti atensi terhadap sensasi tubuh yang muncul saat meregulasi emosi. Penelitian terkini menemukan bahwa perbedaan fokus praktik mindfulness (pada emosi vs. pada pernapasan) menghasilkan kesetaraan rating valensi afek negatif, namun fokus pada pernapasan lebih efektif menurunkan rating perasaan energik (arousal) terhadap stimulus negatif (Beblo dkk., 2018).

Meta-analisis Kohl, Rief, dan Glombleski (2012) menemukan bahwa dibandingkan reappraisal, distraction, dan suppression, komponen mindfulness berupa acceptance lebih unggul untuk meningkatkan toleransi terhadap rasa sakit namun tidak lebih efektif untuk menurunkan intensitas rasa sakit dan afek negatif. Artinya manfaat jangka pendek mindfulness relatif terhadap strategi regulasi emosi lain perlu diukur dalam konteks yang lebih spesifik daripada afek positif dan negatif. Penelitian mendatang dapat menguji efektivitas regulasi emosi mindfulness untuk memperkuat kapasitas self-control individu dalam mencapai goal-oriented functions (self-control ego-depletion: Hagger dkk., 2016; Yusainy \& Lawrence, 2015) dan memori (KaYan, Ginting, \& Cakrangadinata, 2016), serta relatif terhadap konstruk yang mirip seperti ketidakmelekatan terhadap pengalaman (nonattachment: Sahdra, Ciarrochi, \& Parker, 2016). Studi selanjutnya dengan data biologis terukur amat dibutuhkan untuk menggali dinamika emosi-afek pada tingkat proses primer dan sekunder, karena pengukuran respons afektif dalam penelitian ini terbatas pada tingkat proses tersier berupa label yang secara sadar diberikan oleh subjek terhadap stimulus afektif (Panksepp \& Biven, 2012). Upaya mengoptimalkan fungsi emosiafek bagi kehidupan membutuhkan eksplorasi lebih jauh mengenai kompleksitas dinamika respons emosional antara mindfulness dan strategi regulasi emosi lain, dengan memperhatikan berbagai isu metodologis dalam penelitian mindfulness (Van Dam dkk., 2018).

\section{SIMPULAN}

Eksperimen ini menguji efektivitas mindfulness sebagai regulasi emosi yang bersifat person-oriented functions dibandingkan strategi lain dalam Process Model of Emotion Regulation berupa positive reappraisal, distraction, dan suppression, serta kondisi kontrol yang tidak diminta melakukan regulasi apapun. Secara keseluruhan, dapat disimpulkan bahwa mindfulness sama efektifnya dengan positive reappraisal dan suppression ketika stimulus yang dihadapi partisipan berada pada kategori positif, sedangkan efektivitas mindfulness 
lebih rendah dibandingkan positive reappraisal untuk kategori stimulus negatif. Efektivitas mindfulness setara dengan suppression terhadap kategori stimulus negatif. Sementara itu, distraction sama tidak efektifnya dengan kondisi kontrol.

\section{UCAPAN TERIMA KASIH}

Terima kasih kepada Fakultas Ilmu Sosial dan Ilmu Politik Universitas Brawijaya atas dana hibah untuk penelitian ini.

\section{DAFTAR PUSTAKA}

Aldao, A., Nolen-Hoeksema, S., Schweizer, S. (2010). Emotion-regulation strategies across psychopathology: A meta-analytic review. Clinical Psychology Review, 30, 217-237. doi:10.1016/j.cpr.2009.11.004.

Anderson, A. K. (2007). Feeling emotional: The amygdala links emotional perception and experience. Social Cognitive and Affective Neuroscience, 2(2), 71 - 72. doi:10.1093/scan/nsm022

Arch, J., \& Craske M. (2006). Mechanism of mindfulness: Afect regulation following a focused breathing induction. Behavior Research and Therapy, 44, 1849-1858. doi:10.1016/j.brat.2005.12.007

Baer, R. A. (2003). Mindfulness training as a clinical intervention: A conceptual and empirical review. Clinical Psychology: Science and Practice, 10(2), 125-143. doi:10.1093/clipsy.bpg015.

Beblo, T., Pelster, S., Schilling, C. Kleinke, K., Iffland B., Driessen, M., \& Fernando, S. (2018). Breath versus emotions: The impact of different foci of attention during mindfulness meditation on the experience of negative and and positive emotions. Behavior Therapy, 49(5), 702-714. doi:10.1016/j.beth.2017.12.006.
Bradley, M. M., \& Lang, P. J. (2007). The International Affective Picture System (IAPS) in the study of emotion and attention. In J. A. Coan \& J. J. B. Allen (Eds.), Handbook of emotion elicitation and assessment (pp. 29-46). Oxford University Press.

Buhle, J. T., Kober, H., Ochsner, K. N., Mende-Siedlecki, P., Weber, J., Hughes, B. L., ... Wager, T. D. (2013). Common representation of pain and negative emotion in the midbrain periaqueductal gray. Social Cognitive and Affective Neuroscience, 8(6), 609616. doi:10.1093/scan/nss038.

Buhle, J. T., Silvers, J. A., Wager, T. D., Lopez, R., Onyemekwu, C., Kober, H., ... Ochsner, K. N. (2014). Cognitive reappraisal of emotion: A meta-analysis of human neuroimaging studies. Cerebral Cortex, 24, 2981-2990. doi:10.1093/cercor/bht154.

Butler, E., Lee, T., \& Gross, J. (2007) Emotion regulation and culture: Are the social consequences of emotion suppression culture specific? Emotion, $7, \quad 30-48$. doi:10.1037/15283542.7.1.30

Carver, C. S., \& Scheier, M. F. (1982). Control theory: A useful conceptual framework for personality-social, clinical and health psychology. Psychological Bulletin, 92(1), 111135. doi:10.1037/0033-2909.92.1.111

Chiesa, A., Serretti, A., \& Jakobsen, J. (2013). Mindfulness: Top-down or bottom-up emotion regulation strategy? Clinical Psychology Review, 33, $\quad$ 82-96. doi:10.1016/j.cpr.2012.10.006

Cho, S., Lee, H., Oh, K. J., \& Soto, J. A. (2017). Mindful attention predicts greater recovery from negative emotions, but not reduced reactivity. 
Cognition and Emotion, 31(6), 12521259.

doi:10.1080/02699931.2016.1199422.

Dan-Glauser, E. S., \& Gross, J. J. (2015). The temporal dynamics of emotional acceptance: Experience, expression, and physiology. Biological Psychology, 108, 1-12. doi:10.1016/j.biopsycho.2015.03.005.

Diamond, L. M., \& Aspinwall, L.G. (2003). Emotion regulation across the life span: An integrative perspective emphasizing self-regulation, positive affect, and dyadic process. Motivation and Emotion, 27(2), 125 - 156. doi:10.1023/A:1024521920068

Farb, N. A. S., Segal, Z. V., Mayberg, H., Bean, J., McKeon, D., Fatima, Z., \& Anderson, A. K. (2007). Attending to the present: Mindfulness meditation reveals distinct neural modes of selfreference. Social Cognitive and Affective Neuroscience, 2(4), 313-322. doi:10.1093/scan/nsm030.

Folkman, S. (1997). Positive psychological states and coping with severe stress. Social Science and Medicine, 45(8), 1207-1221. doi:1016/S02779536(97)00040-3.

Ford, B. Q., \& Mauss, I. B. (2015). Culture and emotion regulation. Current Opinion in Psychology, 3, 1-5. doi:10.1016/j.copsyc.2014.12.004.

Gotink, R. A, Chu, P., Busschbach, J. J. V., Benson, H, Fricchione, G. L., \& Hunink, M. G. M. (2015). Standardised mindfulness-based interventions in healthcare: An overview of systematic reviews and meta-analyses of RCTs. PLoS ONE 10(4): e0124344. doi:10.1371/journal.pone.0124344.

Gross, J. J., \& Thompson, R. A. (2007). In J. J. Gross (Ed), Handbook of emotion regulation (pp. 3-24). New York: Guilford.

Gruber, J. (2011). A review and synthesis of positive emotion and reward disturbance in bipolar disorder. Clinical Psychology and Psychotherapy, 18(5), 356-365. doi:10.1002/cpp.776.

Gu, J., Strauss, C., Bond, R. \& Cavanagh, K. (2015). How do mindfulness-based cognitive therapy and mindfulnessbased stress reduction improve mental health and wellbeing? A systematic review and meta-analysis of meditation studies. Clinical Psychology Review, 37, 1-12. doi:10.1016/j.cpr.2015.01.006.

Guendelman, S., Medeiros, S., \& Rampes, H. (2017). Mindfulness and emotion regulation: Insights from neurobiological, psychological, and clinical studies. Frontiers in Psychology, $8, \quad 220$. doi:10.3389/fpsyg.2017.00220.

Hagger, M. S., Chatzisarantis, N. L. D., Alberts, H., Anggono, C. O., Batailler, C., Birt, A., ... Zwienenberg, $\mathrm{M}$. (2016). A multilab preregistered replication of the ego-depletion effect. Perspectives on Psychological Science, 11(4), 546-573. doi:10.1177/1745691616652873.

Hayes, S. C., Follette, V. M., \& Linehan, M. (2004). Mindfulness and acceptance: Expanding the cognitive-behavioral tradition. New York: Guilford Press.

Hayes, A. \& Feldman, G. (2004). Clarifying the construct of mindfulness in the context of affect regulation and the process of change in therapy. Behavioural and Cognitive Psychotherapy, 11(3), 255-262. doi:10.1093/clipsy.bph080. 
Hofmann, S. G., Heering, S., Sawyer, A. T., \& Asnaani, A. (2009). How to handle anxiety: The effects of reappraisal, acceptance, and suppression strategies on anxious arousal. Behaviour Research and Therapy, 47(5), 389394. doi:10.1016/j.brat.2009.02.010.

Hu, T. Y., Xie, X., \& Li, J. (2013). Negative or positive? The effect of emotion and mood on risky driving. Transportation Research Part F: Traffic Psychology and Behaviour, 16, 29-40. doi:10.1016/j.trf.2012.08.009.

Immordino-Yang, M. H., \& Singh, V. (2013). Hippocampal contributions to the procession of social emotion. Human Brain Mapping, 34(4), 945 - 955. doi:10.1002/hbm.21485.

KaYan, K., Ginting, H., \& Cakrangadinata, C. (2016). It is fear, not disgust, that enhances memory: Experimental study on students in Bandung. Anima Indonesian Psychological Journal, 31(2), 77-83. doi:10.24123/aipj.v31i2.566.

Keng, S. L., Smoski, M. J., \& Robins, C. J. (2011). Effects of mindfulness on psychological health: A review of empirical studies. Clinical Psychology Review, 31, 1041-1056. doi:10.1016/j.cpr.2011.04.006.

Keng, S. L., Tan, E. L. Y., Eisenlohr-Moul, T. A., \& Smoski, M. J. (2017). Effects of mindfulness, reappraisal, and suppression on sad mood and cognitive resources. Behaviour Research and Therapy, 91, 33-42. doi:10.1016/j.brat.2017.01.006.

Kim, S., \& Hamann, S. (2007). Neural correlates of positive and negative affect regulation. Journal of Cognitive Neuroscience, 19, 776-798. doi:10.1162/jocn.2007.19.5.776.
Kohl, A., Rief, W., \& Glombiewski, J. A. (2012). How effective are acceptance strategies? A meta-analytic review of experimental results. Journal of Behavior Therapy and Experimental Psychiatry, 43, 988-1001. doi:10.1016/j.biopsycho.2015.03.005.

Koole, S. L. (2009). The psychology of emotion regulation: An integrative review. Cognition \& Emotion, 23(1), 441. doi:10.1080/02699930802619031.

Lalot, F., Delplanque, S., \& Sander, D. (2014). Mindful regulation of positive emotions: A comparison with reappraisal and expressive suppression. Frontiers in Psychology, 5, 243. doi:10.3389/fpsyg.2014.00243.

Lang, P. J., Bradley, M. M., \& Cuthbert, B. N. (2008). International affective picture system (IAPS): Affective ratings of pictures and instruction manual. Technical Report A-8. Gainesville, FL: University of Florida.

McRae, K., Hughes, B., Chopra, S., Gabrieli, J., Gross, J., \& Ochsner, K. (2010). The neural bases of distraction and reappraisal. Journal of Cognitive Neuroscience, 22(2), 248-262. doi:10.1162/jocn.2009.21243.

Panksepp, J., \& Biven, L. (2012). The archaeology of mind: Neuroevolutionary origins of human emotions. New York: W. W. Norton and Co.

Phan, K. L., \& Sripada, C. S. (2013). Emotion regulation. In J. Armony \& $\mathrm{P}$. Vuilleumier (Eds), The Cambridge handbook of human affective neuroscience (pp. 373-400). New York: Cambridge University Press.

Peirce, J. W. (2009). Generating stimuli for neuroscience using PsychoPy. 
Frontiers in Neuroinformatics, 2:10. doi:10.3389/neuro.11.010.2008.

Ryan, R. M., \& Deci, E. L. (2000). On happiness and human potentials: A review of research on hedonic and eudaimonic well-being. Annual Review of Psychology, 52, $141-166$. doi:10.1146/annurev.psych.52.1.141.

Sahdra, B., Ciarrochi, J., \& Parker, P. (2016). Nonattachment and mindfulness: Related but distinct constructs. Psychological Assessment, 28, 819829. doi:10.1037/pas0000264.

Shapiro, S. L., Carlson, L. E., Astin, J. A., \& Freedman, B. (2006). Mechanisms of mindfulness. Journal of Clinical Psychology, 62(3), 373-386. doi:10.1002/jclp.20237.

Sharot, T. (2011). The optimism bias. Current Biology, 21(23), R941-R945. doi:10.1016/j.cub.2011.10.030.

Silarus, A. (2015). Sadar penuh, hadir utuh. Jakarta: TransMedia Pustaka.

Soto, J., Perez, C., Kim, Y., Lee, E., \& Minnick, M. (2011). Is expressive suppression always associated with poorer psychological functioning? Cross-cultural comparison between European Americans and Hong-kong Chinese. Emotion, 11, 1450-1455. doi:10.1037/a0023340.

Szasz P. L., Szentagotai, A., \& Hofmann, S. G. (2011). The effect of emotion regulation strategies on anger. Behaviour Research and Therapy, 49, 114-119. doi:10.1016/j.brat.2010.11.011.

Tamir, M., \& Gross, J. J. (2011). Beyond pleasure and pain? Emotion regulation and positive psychology. In K. M. Sheldon, T. B. Kashdan, and M. F. Steger (Eds.), Designing positive psychology: Taking stock and moving forward (pp. 89-100). New York: Oxford University Press.

Thiruchselvam, R., Blechert, J., Sheppes, G., Rydstrom, A., \& Gross, J. J. (2011). The temporal dynamics of emotion regulation: An EEG study of distraction and reappraisal. Biological Psychology, $87(1)$, 84-92. doi:10.1016/j.biopsycho.2011.02.009.

Van Dam, N. T., van Vugt, M. K., Vago, D. R., Schmalzl, L., Saron, C. D., Olendzki, A., ... Meyer, D. E. (2018). Mind the hype: A critical evaluation and prescriptive agenda for research on mindfulness and meditation. Perspectives on Psychological Science, 13(1) 36-61. doi:10.1177/1745691617709589.

Van Dillen, L. F., \& Papies, E. E. K. (2015). From distraction to mindfulness: Psychological and neural mechanisms of attention strategies in self-regulation. In G. H. E. Gendolla, M. Tops, \& S. L. Koole (Eds.), Handbook of biobehavioral approaches to selfregulation $S E-10$ (pp. 141-154). New York: Springer.

Venkatraman, A., Edlow, B. L., \& Immordino-Yang, M. H. (2017). The brainstem in emotion: A review. Frontiers in Neuroanatomy, 11, 15. doi:10.3389/fnana.2017.00015.

Webb, T. L., Miles, E., \& Sheeran, P. (2012). Dealing with feeling: A meta-analysis of the effectiveness of strategies derived from the process model of emotion regulation. Psychological Bulletin, $\quad 138, \quad 775-808$. doi:10.1037/a0027600.

Wilson, T. D., and Gilbert, D. T. (2008). Explaining away: A model of affective adaptation. Perspectives on 
Psychological Science, 3, 370-386. doi:10.1111/j.1745-6924.2008.00085.x

Wolgast, M., \& Lundh, L.-G. (2017). Is Distraction an adaptive or maladaptive strategy for emotion regulation? A person-oriented approach. Journal of Psychopathology and Behavioral Assessment, 39(1), 117-127. doi:10.1007/s10862-016-9570-x.

Yusainy, C. (2017). Feeling full or empty inside? Peran perbedaan individual dalam struktur pengalaman afektif. Jurnal Psikologi, 44(1), 1-17. doi:10.22146/jpsi.18377.
Yusainy, C., Ilhamuddin, I., Ramli, A. H., Semedi, B. P., Anggono, C. O., Mahmudah, M. U., Ramadhan, A. R. (2018). Between here-and-now and hereafter: Mindfulness sebagai pengawal orientasi terhadap kehidupan dan ketakutan terhadap kematian. Jurnal Psikologi, 17(1), 18-30. doi:10.14710/jp.17.1.18-30.

Yusainy, C., \& Lawrence, C. (2015). Brief mindfulness induction could reduce aggression after depletion. Consciousness and Cognition, 33(1), 125-134.

doi:10.1016/j.concog.2014.12.008. 